\title{
Plasticidade fenotípica como indicador de arbóreas não pioneiras mais tolerantes à elevada luminosidade
}

\author{
Inayá Castiglioni Paradizo ${ }^{1}$, Bernardo Pretti Becacici Macieira ${ }^{1}$, Vinícius Novo Gama ${ }^{1}$, Leonardo Valandro Zanetti ${ }^{1}$, \\ Geraldo Rogério Faustini Cuzzuol ${ }^{1 *}$
}

${ }^{1}$ Universidade Federal do Espírito Santo, Av. Fernando Ferrari 514, CEP 29075-910, Vitória, ES, Brasil

\author{
*Autor correspondente: \\ gcuzzuol@gmail.com \\ Termos para indexação: \\ Crescimento \\ Anatomia Foliar \\ Cariniana legalis \\ Paratecoma peroba
}

\author{
Index terms: \\ Growth \\ Foliar anatomy \\ Cariniana legalis \\ Paratecoma peroba
}

\section{Histórico do artigo:}

Recebido em 25/05/2015

Aprovado em 26/11/2015

Publicado em 31/12/2015

\begin{abstract}
Resumo - A ocorrência de Cariniana legalis (Mart.) Kuntze (Lecythidaceae) em florestas secundárias em diferentes fases de regeneração sugere que essa espécie seja mais resistente a pleno sol em relação a Paratecoma peroba (Record. \& Mell) Kuhlm. (Bignoniaceae) encontrada no interior da floresta primária densa. O objetivo desse trabalho foi caracterizar a plasticidade das variáveis de crescimento, anatômicas e estruturais de parede celular de C. legalis e P. peroba. Como o caule é forte dreno em arbóreas, foi elaborada a hipótese que as plasticidades das ligninas e dos monossacarídeos das hemiceluloses são maiores em relação às variáveis de crescimento e anatômicas, especialmente em C. legalis, mais resistente a pleno sol, como sugere seu hábito ecológico. Plantas jovens, com 14 meses de idade, foram submetidas a 20 e $100 \%$ de luminosidade solar por 60 dias. Diferente do esperado, a plasticidade das ligninas foi inferior a das variáveis de crescimento e anatômicas para as duas espécies. A composição das hemiceluloses de C. legalis não foi influenciada pela luminosidade. Em P. peroba, a proporção de arabinose foi menor a pleno sol. Concluímos que a indicação de maior resistência de $C$. legalis a pleno sol foi associada ao índice de plasticidade das taxas de assimilação líquida e de crescimento relativo $(\geq 0,6)$, densidade estomática $(\geq 0,3)$ e ligninas $(\leq 0,2)$.
\end{abstract}

\section{Phenotypic plasticity as indicator of no pioneer trees more tolerant to intense irradiance}

\begin{abstract}
The occurrence of Cariniana legalis (Mart.) Kuntze (Lecythidaceae) in secondary forests in different levels of regeneration suggests that this species is more resistant to full sun in relation to Paratecoma peroba (Record. \& Mell) Kuhlm. (Bignoniaceae) found in dense primary forest. The aim of this study was to characterize the plasticity of growth, anatomical and structural cell wall variables of $C$. legalis and $P$. peroba. As the stem is strong drain on tree, it was proposed the hypothesis that plasticity of lignin and hemicelluloses monosaccharides are higher than of growth and anatomical variables, especially with $C$. legalis that is more resistant to full sun as suggested by its ecological habit. Young plants with 14 months of age were subjected to 20 and $100 \%$ of solar light for 60 days. Unlike expected, the plasticity of lignin was lower than plasticity of growth and anatomic variables for both species. Hemicellulose composition of $C$. legalis was not affected by light. Proportion of arabinose was lower in $P$. peroba under full sun. We conclude that the indication of higher resistance of C. legalis to full sun was associated with plasticity index of net assimilation rate and relative growth rate $(\geq 0.6)$, stomatal density $(\geq 0.3)$ and lignins $(\leq 0.2)$.
\end{abstract}




\section{Introdução}

A capacidade de um genótipo em expressar a amplitude dos caracteres adaptativos em resposta às variações ambientais é conhecida como plasticidade fenotípica (Chambel et al., 2005; Bradshaw, 2006). Espécies mais plásticas têm maior chance de sobreviver às variações contrastantes do ambiente, em virtude de sua capacidade de adaptações morfológicas, fisiológicas e bioquímicas (Valladares et al., 2005).

A plasticidade fenotípica vem sendo amplamente investigada em espécies vegetais sob luminosidade contrastante, pelo fato da luz ser um dos fatores ambientais mais decisivos na sobrevivência das plantas (Poorter, 2001). As espécies florestais pioneiras, por colonizarem locais da floresta sujeitos à elevada luminosidade, são reconhecidas pela sua maior plasticidade e capacidade de resistência à elevada intensidade luminosa (Walter, 2005; Valladares \& Niinemets, 2008).

Há indicações de que tanto espécies pioneiras quanto as não pioneiras têm plasticidade potencial de ajustes às variações da intensidade luminosa, que não está, necessariamente, relacionada ao grupo funcional (Rozendaal et al., 2006; Souza et al., 2009) mas sim às diferenças interespecíficas (Oguchi et al., 2005). Recentemente, Gaburro et al. (2014) demonstraram que espécies tropicais não pioneiras possuem plasticidade potencial para se ajustarem às variações intensas da intensidade da luminosidade, com as variáveis relacionadas à fotossíntese, sendo mais plásticas do que as variáveis de crescimento, anatômicas e bioquímicas.

Considerando que o caule das árvores representa 90\% da biomassa seca das plantas (Körner, 2003), tem sido especulado que variações da intensidade da luminosidade possam interferir no teor e na plasticidade dos polímeros da parede celular desse órgão dreno (Zani, 2014). Os principais compostos da parede celular são as celuloses, hemiceluloses e as ligninas. Estruturalmente, as hemiceluloses estão interligadas com as microfibrilas da celulose através de ligações de hidrogênio (Cosgrove, 2000; Thompson, 2005). Na maioria das espécies arbóreas, as hemiceluloses mais representativas do caule são os xilanos (Shädel, 2010a). Estes são formados por uma estrutura linear constituída de xilopiranosil unidos por ligações $\beta-1,4$ na cadeia principal e diferentes unidades monossacarídicas (Saha, 2003). O xiloglucano é o principal tipo de hemicelulose em paredes primárias de eudicotiledôneas (Carpita \&
McCann, 2000). É formado por uma cadeia principal de glicoses com ligação $\beta$-1,4 e ramificações de xiloses com ligação $\alpha-1,6$ (Fry et al., 1993).

A lignina é um polímero complexo, com estrutura de natureza aromática e alto peso molecular. É formado por diversas combinações de três tipos de resíduos: lignina guaiacila, siringila e $p$-hidroxifenila (Fengel \& Wegener, 1989), que são sintentizadas a partir da oxidação desidrogenerativa de três alcoóis monolignóis (coniferílico, sinapílico e $p$-cumarílico, respectivamente) (Raes et al., 2003).

As ligninas e as hemiceluloses são bem estudadas, devido ao forte apelo comercial desses polímeros na produção de biocombustíveis (Saha, 2003; Gray et al., 2006; Somerville, 2007. Pauly \& Keegstra, 2008). No entanto, é desconhecida a influência das variações ambientais no teor desses polímeros e na composição química das hemiceluloses. $\mathrm{O}$ enriquecimento do $\mathrm{CO}_{2}$ pode elevar a proporção da glucose das hemiceluloses de espécies arbóreas de regiões temperadas (Shädel et al., 2010b) e reduzir o teor de lignina da espécie tropical pioneira Senna reticulata (Arenque et al., 2014). Quanto ao aumento da temperatura e irradiância previsto pelo Painel intergovernamental sobre as mudanças climáticas para as próximas décadas, sabe-se que a maior intensidade de luminosidade estimula a lignificação (Narendra et al., 2007). Com relação às hemiceluloses, é desconhecida a influência do aumento da intensidade da luminosidade na proporção de seus monossacarídeos. Desconhece-se, também, se a plasticidade das ligninas e dos componentes das hemiceluloses é maior ou menor em relação às variáveis de crescimento e anatômicas em arbóreas tropicais não pioneiras sob intensidade de luminosidade contrastante.

O presente estudo teve o objetivo de identificar as variáveis fenotípicas de maior plasticidade em espécie não pioneira mais resistente a pleno sol. Para tanto, utilizamos as espécies não pioneiras Paratecoma peroba (Record. \& Mell) Kuhlm. (Bignoniaceae) e Cariniana legallis (Mart.) Kuntze (Lecythidaceae) de grande valor para a indústria madeireira e de distribuição neotropical da floresta Atlântica do Brasil (Lorenzi, 1992). A ocorrência de $P$. peroba no interior da floresta primária densa (Lorenzi, 2002) sugere que essa espécie seja menos resistente a pleno sol em relação a $C$. legalis, encontrada na floresta secundária e capoeirões (Rondon Neto et al., 1999). Como o caule é forte dreno em arbóreas, foi elaborada a hipótese de que a plasticidade 
das ligninas e dos monossacarídeos das hemiceluloses são maiores em relação às variáveis de crescimento e anatômicas, especialmente na espécie mais resistente a pleno sol C. legallis, como sugere seu hábito ecológico.

\section{Material e métodos}

Sementes de Paratecoma peroba (Record.) Kuhlm. (Bignoniaceae) e Cariniana legallis (Raddi.) Kuntze (Lecythidaceae) foram coletadas na Floresta Tropical Estacional Semidecídua perenifólia (Engel, 2001) da

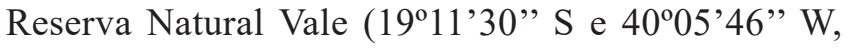
altitude $58 \mathrm{~m}$ ), localizada em Sooretama, ES, Brasil.

A densidade de fluxo de fótons fotossintéticos (DFFF) do sub-bosque foi medida na estação de baixa precipitação (20 de agosto de 2012) com um espectrorradiômetro (Spectrum Technologies, Inc., Illinois, EUA), em dez locais da floresta onde ocorrem as duas espécies, a um metro do solo, obtendo-se valor médio de $400 \pm 100$ de $\mu \mathrm{mol} \mathrm{m} \mathrm{m}^{-2} \mathrm{~s}^{-1}$.

As sementes foram germinadas em bandejas plásticas com areia lavada, em câmara de germinação com fotoperíodo de $12 \mathrm{~h}$ e temperatura de $25^{\circ} \mathrm{C}$. Após a germinação, as plântulas foram transplantadas para vasos de polietileno de $12 \mathrm{~L}$, contendo mistura de terra vegetal, areia e argila (1:1:1) e mantidas sob $400 \mu \mathrm{mol} \mathrm{m}^{-2} \mathrm{~s}^{-1} \mathrm{da}$ DFFF (20\% da DFFF a pleno sol) em telado sombrite, com temperatura média de $28 \pm 2{ }^{\circ} \mathrm{C}$, umidade relativa de $75 \pm 8 \%$ e fotoperíodo natural de $11 \pm 1 \mathrm{~h}$, no Campus da Universidade Federal do Espírito Santo, em Vitória, ES. Após 14 meses de cultivo nessas condições, um lote das plantas permaneceu nessa condição e outro foi transferido para pleno sol, correspondendo, em média, a 2.000 $\pm 80 \mu \mathrm{mol} \mathrm{m}^{-2} \mathrm{~s}^{-1}$ da DFFF às 9:00 h de um dia ensolarado no local de estudo. As plantas foram regadas semanalmente, em capacidade de campo, para evitar a deficiência hídrica.

No dia inicial e 60 dias após o início do tratamento, foram realizadas medidas de crescimento em sete plantas por tratamento. Com um paquímetro digital, foram medidos o comprimento e diâmetro do caule. A massa seca das raízes (MSR), caule (MSC) e folhas (MSF) foi medida após secagem em estufa a $60{ }^{\circ} \mathrm{C}$, até a obtenção da massa constante, calculando-se, posteriormente, a massa seca total (M) e massa seca da parte aérea (PA). A área foliar (A) foi medida utilizandose scanner de geração de imagens (Area Meter da LICOR 3100, Nebrasca, EUA). Com esses dados foram calculados: área foliar específica $(\mathrm{AFE}=\mathrm{A} / \mathrm{MSF})$, taxa de crescimento relativo $\left(\mathrm{TCR}=\left(\mathrm{LnM}_{2}-\mathrm{LnM}_{1}\right) /\left(\mathrm{t}_{2}-\mathrm{t}_{1}\right)\right)$, taxa assimilatória líquida $\left(\mathrm{TAL}=\left[\left(\mathrm{LnA}_{2}-\mathrm{LnA}_{1}\right) /\left(\mathrm{A}_{2}\right.\right.\right.$ $\left.\left.\left.-\mathrm{A}_{1}\right)\right] \times\left[\left(\mathrm{M}_{2}-\mathrm{M}_{1}\right) / \mathrm{t}_{2}-\mathrm{t}_{1}\right]\right)$, razão de área foliar (LAR $=\mathrm{A} / \mathrm{M})$, razão MSR: PA (R:PA), alocação de biomassa dada pela razão da massa seca de cada compartimento vegetal dividido pela massa seca total, segundo Lambers \& Poorter (1992), onde, ${ }_{1}=$ valor da variável no tempo inicial; ${ }_{2}=$ valor da variável no tempo final; $\mathrm{t}=$ tempo; $\mathrm{Ln}=\mathrm{Log}$ natural.

Segmentos de caule com massa fresca média de $0,75 \mathrm{~g}$ (1 cm de comprimento) foram retirados a $5 \mathrm{~cm}$ de distância da base do caule das sete plantas de cada tratamento. Esse material foi congelado em nitrogênio líquido, armazenado em ultrafreezer a -70 ${ }^{\circ} \mathrm{C}$ e posteriormente liofilizado (Terrone modelo LS 3000). Antes da extração, os fragmentos de caule, sem a casca, foram triturados em moinho MicroWiley (American Society for Testing and Materials, 2001c). A extração foi realizada em Soxhlet com solução de tolueno:etanol (2:1) por $4 \mathrm{~h}$, seguido pela extração em etanol $99^{\circ} \mathrm{GL}$ por $4 \mathrm{~h}$, finalizando com água a $100^{\circ} \mathrm{C}$, conforme protocolo de ASTM E 1690-01 (American Society for Testing and Materials, 2001a). A fase sólida livre de extrativos foi seca e reservada para as análises da composição química da parede celular. Desse material, pesouse $100 \mathrm{mg}$ para hidrólise dos polissacarídeos de parede celular em solução de $\mathrm{H}_{2} \mathrm{SO}_{4} 72 \%$ a $30{ }^{\circ} \mathrm{C}$ por $1 \mathrm{~h}$, diluída até a concentração aproximada de $2,5 \%$ de ácido $\mathrm{H}_{2} \mathrm{SO}_{4}$ e autoclavada em $121{ }^{\circ} \mathrm{C}$ por $1 \mathrm{~h}$. As amostras foram rapidamente resfriadas em temperatura ambiente e filtradas a vácuo em membrana $47 \mathrm{~mm}$. O filtrado foi utilizado para a determinação dos monossacarídeos de parede celular (glicose, xilose, galactose, arabinose, ramnose e fucose), usando HPAE-PAD (high performance anion exchange - pulsed amperometric detection) (American Society for Testing and Materials, 2001b) em cromatógrafo ICS 2500 da Dionex ${ }^{\circledR}$ equipado com DS50 gradiente; detector e padrões da Sigma ${ }^{\circledR}$, utilizando-se L-fucose como padrão interno. $\mathrm{O}$ eluente de arraste utilizado foi $\mathrm{H}_{2} \mathrm{O}$ milliQ e o eluente de limpeza foi $200 \mathrm{mM}$ de $\mathrm{NaOH}$, com fluxo de $25 \mu \mathrm{L} \cdot \mathrm{min}^{-1}$. O eluente de pós- 
coluna utilizado foi $300 \mathrm{mM}$ de $\mathrm{NaOH}$ com pressão de gás nitrogênio externo. As amostras foram injetadas com volume de $25 \mu \mathrm{L}$. A coluna utilizada foi de troca aniônica Dionex ${ }^{\circledR}$ CarboPac PA10 ( 2 x $250 \mathrm{~mm}$ ) com coluna-guarda CarboPac PA10 ( $2 \times 50 \mathrm{~mm})$. O detector amperométrico associado ao eletrodo de ouro foi ajustado aos potenciais: $+100 \mathrm{mV}$ (0 a $200 \mathrm{~ms}$ ), +100 mV de integração (200 a $400 \mathrm{~ms}),-2000 \mathrm{mV}(410$ a $420 \mathrm{~ms})$, $+600 \mathrm{mV}(430 \mathrm{~ms})$ e $-100 \mathrm{mV}$ (440 a $500 \mathrm{~ms})$.

As ligninas de Klason (insolúveis) e solúveis das sete plantas por tratamento foram determinadas por análise gravimétrica e por espectrofotometria, de acordo com os protocolos de ASTM E 1721-01 (American Society for Testing and Materials, 2001b) e TAPPI T 222 om-88 (Technical Association of the Pulp and Paper Industry, 1998), respectivamente. O resíduo livre de extrativos foi usado para determinação gravimétrica da lignina insolúvel de Klason. A quantificação da lignina solúvel foi determinada espectrofotometricamente e calculada com as medidas de absorbância nos comprimentos de onda de 215 e $280 \mathrm{~nm}$.

Segmentos das folhas expandidas do $4^{\circ}$ nó do ápice para baixo do caule principal das sete plantas por tratamento foram fixados em FAA 70 (formaldeído, ácido acético e etanol 70\%) por $48 \mathrm{~h}$ (Johansen, 1940) e armazenadas em álcool 70\%. Cortes transversais do terço mediano do limbo, compreendendo as regiões internevural e da nervura central das folhas, foram realizados à mão livre com lâminas de aço. Os cortes foram corados com Safrablau (Bukatsch, 1972, modificado) e as lâminas histológicas montadas com água glicerinada (3:1). Para a quantificação estomática fez-se a impressão da epiderme foliar em lâmina de vidro, com éster de cianoacrilato (Super Bonder ${ }^{\circledR}$ ). As observações e a documentação fotográfica foram realizadas em fotomicroscópio (Nikon, Eclipse E200, Tóquio, Japão).

A plasticidade representa a variação do fenótipo da espécie, de acordo com as respostas adaptativas encontradas nos dois tratamentos em que as plantas foram submetidas. O índice de plasticidade fenotípica, com variação de 0 a 1 , foi calculado para cada variável, como sendo a diferença entre o maior e o menor valor médio entre os tratamentos, dividido pelo maior valor médio. Quanto maior o valor do IP, ou seja, quanto mais próximo de 1, mais plástica é a variável (Valladares et al., 2005).
O delineamento adotado foi inteiramentecasualizado, consistindo em esquema fatorial $2 \times 2$ com duas espécies (P. peroba e C. legalis) e duas condições de luminosidade (pleno sol e sombra). Para cada tratamento, foram utilizadas sete plantas. Os dados apresentaram distribuição normal e foram submetidos à análise de variância (ANOVA two-way). As médias foram comparadas pelo teste de Tukey $(\mathrm{P} \leq 0,05)$, utilizando o software Assistat versão 7.5 beta (Silva \& Azevedo, 2007).

\section{Resultados e discussão}

As maiores diferenças das medidas de crescimento entre os dois tratamentos foram encontradas em $P$. peroba (Tabela 1). Plantas dessa espécie apresentaram maior diâmetro caulinar a pleno sol, bem como maior área foliar total e massa seca total à sombra. Essas medidas não diferiram entre as plantas de $C$. legalis nas duas intensidades de luminosidade. A altura e a R:PA não variaram entre os dois tratamentos para as duas espécies. As razões relacionadas à área foliar só diferiram em plantas de $P$. peroba com maiores valores da AFE à sombra e da RAF a pleno sol. As diferenças nas taxas de crescimento foram marcantes para as duas espécies. P. peroba se destacou pela maior TCR e TAL à sombra, enquanto $C$. legalis apresentou maiores valores dessas taxas a pleno sol. Quanto à alocação de biomassa, as duas espécies mostraram maior RMF à sombra e maior RMR a pleno sol. Para a RMC, as plantas de P. peroba mostraram maior valor a pleno sol e nenhuma diferença foi constatada para essa medida em C. legalis entre os dois tratamentos.

Analisando apenas as razões e as taxas entre as duas espécies dentro de cada tratamento (Tabela 1), nota-se que a R:PA e AFE foi maior a pleno sol e à sombra das plantas de $P$. peroba em relação a $C$. legalis. A RAF não se diferenciou entre as duas espécies a pleno sol, mas foi maior à sombra em plantas de C. legalis. A TCR e a TAL foi maior a pleno sol para as plantas de $C$. legalis e maiores nas plantas sombreadas de $P$. peroba. A RMF e RMR não se diferenciaram entre as duas espécies nos dois tratamentos. A RMC foi maior a pleno sol nas plantas de $P$. peroba em relação a C. legalis. No entanto, essa razão não se diferenciou à sombra entre as duas espécies.

As diferenças das medidas de crescimento entre os tratamentos refletiram no IP, porém com valores muito baixos e inferiores a 0,5 (Tabela 1 ), exceto para TCR e 
TAL das plantas de C. legalis, que apresentaram IP 0,84 e 0,63 , respectivamente. Essa espécie se destacou ainda pelo maior IP da R:PA $(0,36)$. P. peroba se caracterizou pelo maior IP do diâmetro caulinar $(0,31)$, da AFT $(0,26), \operatorname{MST}(0,42), \operatorname{AFE}(0,55)$ e RAF $(0,24)$. Nenhuma diferença ocorreu para o IP da RMF, RMC e RMR.

Ainda que pertencentes à mesma classe funcional, as duas espécies não pioneiras apresentaram diferenças interespecíficas aos tratamentos com algumas indicações de que C. legalis é mais resistente a pleno sol do que $P$. peroba. Essa afirmativa é sustentada pela menor produção de AFT e MST de $P$. peroba a pleno sol e pela falta de variação dessas variáveis nas plantas de $C$. legalis entre os tratamentos. Outro aspecto que apoia a maior resistência dessa espécie a pleno sol são os maiores valores da TCR e TAL de C. legalis nessa condição em relação a $P$. peroba.

Tabela 1. Medidas das variáveis de crescimento ( \pm erro padrão) e índice de plasticidade (IP) de plantas de Paratecoma peroba e Cariniana legalis após 60 dias de cultivo a pleno sol e à sombra.

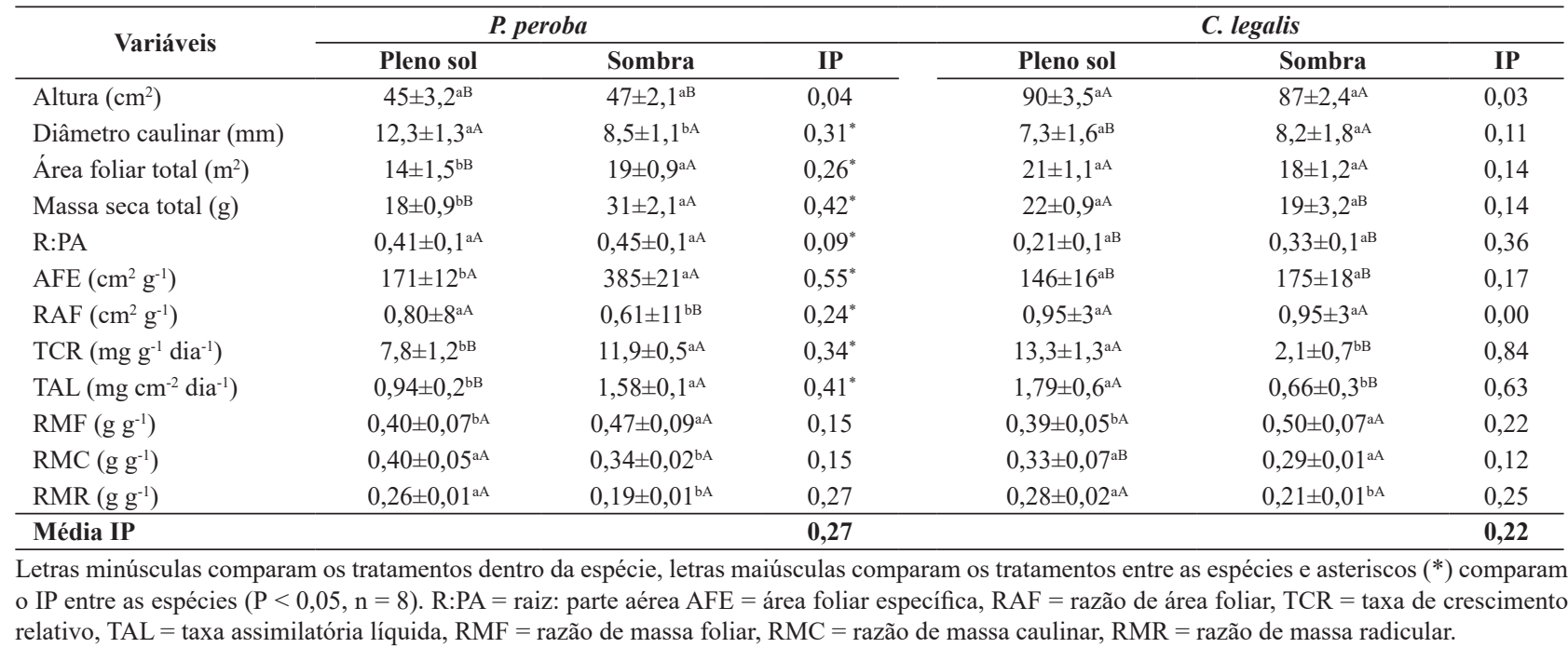

Das variáveis de crescimento, AFE mostrou maior relação com o nível de resistência das duas espécies. Enquanto em $P$. peroba a AFE variou $125 \%$ entre sol e sombra, em $C$. legalis esse valor foi de apenas $20 \%$, confirmando que as espécies mais resistentes à elevada luminosidade apresentam baixa variação da AFE nessa condição (Mengarda et al., 2009; Portela, 2012; Gaburro et al., 2014). Diferente das informações anteriores de que as espécies não pioneiras são menos plásticas e, por isso, menos resistentes a luz solar direta (Walter, 2005; Valladares \& Niinemets, 2008), as plantas de P. peroba e C. legalis avaliadas no presente estudo apresentaram 100\% de sobrevivência a pleno sol (dados não apresentados), com capacidade de ajustes morfológicos interespecíficos (Tabela 1).

A capacidade de ajustes de crescimento à intensidade da luminosidade contrastante não está, necessariamente, relacionada ao grupo funcional (Rozendaal et al., 2006; Souza et al., 2009), mas às diferenças interespecíficas (Oguchi et al., 2005). Algumas das espécies não pioneiras crescem melhor em ambientes mais iluminados e outras em ambientes mais sombreados. Isso parece estar associado com a capacidade de assimilação do carbono. A espécie não pioneira Cedrela odorata L. (Meliaceae) apresentou maior TAL a pleno sol e plasticidade considerável dessa variável em relação às espécies não pioneiras Cariniana estrellensis (Raddi) Kuntze (Lecythidaceae) e Manilkara salzmannii (A. DC.) H.J. Lam. (Sapotaceae), menos resistentes a pleno sol (Gaburro et al., 2014). Nesse sentido, a maior resistência de C. legalis a pleno sol parece ter relação com a maior TAL nessa condição e, consequentemente, com a sua maior plasticidade. Curiosamente, a plasticidade da TAL de $C$. legalis nesse estudo $(0,63)$ foi idêntica ao encontrado em C. odorata (Gaburro et al., 2014). Tais resultados sugerem que espécies não pioneiras mais resistentes à elevada luminosidade apresentam índice de plasticidade da TAL acima de 0,6. A validade dessa hipótese depende da ampliação do número de espécies estudadas nas condições ambientais testadas ou de 
uma meta-análise com espécies arbóreas tropicais não pioneiras.

A maior sensibilidade de $P$. peroba a pleno sol pode estar associada ao maior diâmetro do caule e teor de lignina, sugerindo maior força do dreno caulinar nessa condição ambiental. Dada à íntima relação fonte-dreno, a maior atividade do dreno (caule) de P. peroba a pleno sol deve ter exigido profundos ajustes morfológicos do órgão fonte (folha), como indicado pela maior plasticidade da AFE e da RAF nessa condição ambiental.

A menor resistência de $P$. peroba a pleno sol pode ser confirmada através do maior investimento na área foliar fotossinteticamente ativa em relação à massa seca total (RAF), mas sem capacidade de elevar a TAL. Ou seja, a estratégia de investir na área foliar não foi acompanhada pela indicação de aumento da eficiência fotossintética, como constatado na arbórea tropical não pioneira Cariniana estrellensis, sensível a pleno sol (Portela, 2012).

Quanto à alocação de biomassa, embora a exposição a pleno sol tenha estimulado a maior alocação de biomassa caulinar (RMC) e radicular (RMR) e menor alocação de biomassa foliar (RMF) nas duas espécies, a intensidade da luminosidade não influenciou a plasticidade dessas variáveis, mostrando falta de relação da alocação de biomassa com o nível de resistência. Isto indica uma possível falta de variação na plasticidade da alocação de biomassa também observada em arbóreas juvenis não pioneiras de florestas tropicais do Brasil, sob luminosidade contrastante (Gaburro et al., 2014).

Quanto aos aspectos anatômicos (Tabela 2), nenhuma diferença foi observada na espessura das cutículas e epidermes das duas espécies entre as duas condições de luminosidade. Os parênquimas paliçádico e esponjoso apresentaram maior espessura nas plantas de $P$. peroba a pleno sol. $C$. legalis se destacou pela falta de variação na espessura do parênquima paliçádico e pela maior espessura do parênquima esponjoso à sombra. Essas medidas refletiram na espessura do limbo, sendo que as duas espécies mostraram maior valor dessa variável a pleno sol. A intensidade da luminosidade influenciou no número de estômatos por área nas plantas de $C$. legalis, que mostraram maior densidade a pleno sol. Comparando as duas espécies dentro de cada tratamento, de maneira geral, C. legalis mostrou maiores valores da espessura das estruturas foliares e da densidade estomática em relação a $P$. peroba, tanto a pleno sol quanto à sombra. Porém, a cutícula abaxial e parênquima paliçádico não se diferenciaram entre as duas espécies a pleno sol. Da mesma forma, a densidade estomática também não variou entre as duas espécies à sombra.

Tabela 2. Medidas das variáveis de anatomia foliar das plantas de Paratecoma peroba e Cariniana legalis após 60 dias de cultivo a pleno sol e à sombra.

\begin{tabular}{|c|c|c|c|c|c|c|}
\hline \multirow{2}{*}{ Variáveis } & \multicolumn{2}{|c|}{ P. peroba } & \multirow[b]{2}{*}{ IP } & \multicolumn{3}{|c|}{ C. legalis } \\
\hline & Pleno sol & Sombra & & Pleno sol & Sombra & IP \\
\hline Cutícula adaxial (mm) & $4,4 \pm 0,5^{\mathrm{aB}}$ & $4,8 \pm 0,7^{\mathrm{aB}}$ & $0,08^{*}$ & $5,8 \pm 0,3^{\mathrm{aA}}$ & $6,9 \pm 0,6^{\mathrm{aA}}$ & 0,16 \\
\hline Cutícula abaxial (mm) & $3,9 \pm 0,9^{\mathrm{aA}}$ & $3,6 \pm 0,7^{\mathrm{aB}}$ & $0,07^{*}$ & $4,8 \pm 0,5^{\mathrm{aA}}$ & $4,9 \pm 0,4^{\mathrm{aA}}$ & 0,02 \\
\hline Epiderme adaxial $(\mathrm{mm})$ & $28 \pm 3,6^{\mathrm{aB}}$ & $32 \pm 4,5^{\mathrm{aB}}$ & $0,12^{*}$ & $49 \pm 5,3^{\mathrm{aA}}$ & $46 \pm 4,2^{\mathrm{aA}}$ & 0,06 \\
\hline Epiderme abaxial (mm) & $23 \pm 1,9^{\mathrm{aB}}$ & $25 \pm 2,4^{\mathrm{aB}}$ & 0,08 & $36 \pm 4,9^{\mathrm{aA}}$ & $38 \pm 3,8^{\mathrm{aA}}$ & 0,05 \\
\hline Parênquima paliçádico (mm) & $135 \pm 8,1^{\mathrm{aA}}$ & $115 \pm 6,8^{\mathrm{bB}}$ & $0,15^{*}$ & $140 \pm 5,7^{\mathrm{aA}}$ & $135 \pm 8,2^{\mathrm{aA}}$ & 0,03 \\
\hline Parênquima esponjoso (mm) & $107 \pm 6,4^{\mathrm{aB}}$ & $90 \pm 8,8^{\mathrm{bB}}$ & $0,16^{*}$ & $235 \pm 12^{\mathrm{bA}}$ & $254 \pm 8,51^{\mathrm{aA}}$ & 0,07 \\
\hline Limbo $(\mathrm{mm})$ & $216 \pm 10,2^{\mathrm{aB}}$ & $183 \pm 8,3^{\mathrm{bB}}$ & $0,15^{*}$ & $374 \pm 6,8^{\mathrm{aA}}$ & $356 \pm 13,8^{\mathrm{bA}}$ & 0,05 \\
\hline Densidade estomática $\left(\mathrm{mm}^{2}\right)$ & $26 \pm 0,01^{\mathrm{aB}}$ & $21 \pm 0,02^{\mathrm{aA}}$ & $0,19^{*}$ & $33 \pm 2,5^{\mathrm{aA}}$ & $23 \pm 3,6^{\mathrm{bA}}$ & 0,30 \\
\hline Média IP & & & 0,17 & & & 0,15 \\
\hline
\end{tabular}

Letras minúsculas comparam tratamentos dentro de espécie, letras maiúsculas comparam tratamentos entre as espécies e asteriscos (*) comparam o índice de plasticidade (IP) entre as espécies $(P<0,05, \mathrm{n}=8)$.

Analisando a plasticidade das variáveis anatômicas das duas espécies nos dois tratamentos (Tabela 2), P. peroba apresentou maiores IP da cutícula abaxial, epiderme adaxial, parênquima paliçádico, parênquima esponjoso e limbo. C. legalis se destacou pelo maior IP da cutícula adaxial e da densidade estomática. Somente a epiderme abaxial não mostrou diferença do IP entre as duas espécies. Os IP das variáveis anatômicas foram muito baixos, não ultrapassando 0,3 (densidade estomática de C. legalis).

A menor resistência de $P$. peroba em povoar ambientes mais iluminados também pode ser confirmada pelo maior espessamento do parênquima paliçádico e esponjoso a pleno sol. Esses tecidos alongaram 17\% em P. peroba a pleno enquanto em $C$. legalis alongam pouco, demonstrando certa relação da plasticidade dos seus 
tecidos parenquimáticos com a resistência a pleno sol. A maior resistência de $C$. legalis a pleno sol parece ter relação com a baixa capacidade de ajustes das dimensões celulares dos parênquimas a pleno sol (Mengarda et al., 2012), enquanto o inverso foi verificado em $P$. peroba. Embora seja relatado que o parênquima paliçádico de espécies pioneiras apresente maior alongamento do que as não pioneiras sob intensa luminosidade (Hanba et al., 2002), algumas espécies não pioneiras das florestas tropicais também têm mostrado expressiva capacidade de alongamento do parênquima paliçádico quando submetidas a pleno sol (Mengarda et al., 2012; Portela, 2012). Em alguns casos, esse aumento pode representar até $50 \%$ do tamanho das células do parênquima paliçádico das plantas mantidas à sombra (Gaburro et al., 2014). Devido a respostas divergentes, podemos concluir que a plasticidade do parênquima paliçádico não é um bom indicador de resistência a pleno sol de espécies não pioneiras.

O alongamento do parênquima paliçádico consiste em uma eficiente estratégia para evitar a foto-oxidação e minimizar o dano metabólico causado pela maior temperatura associada à elevada intensidade da luminosidade (Rossato \& Kolb, 2012). De fato, o espessamento das folhas a pleno sol consiste em uma das estratégias para minimizar a oxidação dos pigmentos cloroplastídicos sob elevada luminosidade (Navas \& Garnier, 2002), sem comprometer a fixação de $\mathrm{CO}_{2}$. Essa estratégia de fuga aos fotodanos não evitaram a redução da TAL nas plantas de $P$. peroba a pleno sol, corroborando com resultados anteriores de que algumas espécies não pioneiras tropicais tendem a apresentar maior TAL quando expostas ao sol (Souza \& Válio, 2003; Mengarda et al., 2009; Portela, 2012; Gaburro et al., 2014).

A maior TAL a pleno sol pode ser decorrente da maior densidade estomática associada à maior eficiência na assimilação de $\mathrm{CO}_{2}$ e reduzida perda de água por transpiração (Mendes et al., 2001). Isso demonstra que a plasticidade da densidade estomática, semelhante às outras variáveis morfológicas, são interespecíficas e independentes da classe funcional.

Com exceção da TAL associada às reações fotoquímicas e de assimilação do carbono, a plasticidade das variáveis anatômicas e de crescimento mostraram valores muito baixos, confirmando, assim, que as variáveis estruturais são menos plásticas do que as variáveis relacionadas à fotossíntese, conforme postulado por Givnish (1981) e evidenciado mais recentemente em espécies arbóreas tropicais (Rozendaal et al., 2006; Barros et al., 2012; Portela , 2012; Gaburro et al., 2014).

Com relação aos componentes de parede celular do xilema secundário do caule, poucas diferenças foram observadas (Tabela 3). A proporção de glicose foi maior a pleno sol nas duas espécies, correspondendo a 48-49\% da massa seca. A proporção de arabinose em P. peroba foi maior à sombra, mas não se diferenciou entre os dois tratamentos em C. legalis. Os demais monossacarídeos estruturais não variaram entre pleno sol e sombra nas duas espécies. Quanto às ligninas, as plantas de P. peroba a pleno sol apresentaram maior teor de lignina de Klason, representando $23 \%$ da massa seca. Nenhuma diferença foi verificada no teor de lignina de Klason em plantas de C. legalis entre pleno sol e sombra. A lignina solúvel não variou entre os dois tratamentos para as duas espécies.

Comparando os componentes de parede celular entre as espécies na mesma condição de luminosidade, só foram constatadas diferenças entre as espécies à sombra. Nessa condição, $P$. peroba apresentou maior proporção de arabinose, enquanto $C$. legalis se destacou pelo maior teor de lignina de Klason. Independente da espécie e do tratamento, os monossacarídeos de parede celular seguiram o mesmo padrão de proporcionalidade com glicose $>$ xilose $>$ galactose $>$ arabinose $>$ ramnose $>$ fucose.

A baixa variação dos componentes de parede celular entre os dois tratamentos pouco influenciou no IP com valores inferiores a 0,5 . A arabinose mostrou maior IP em P. peroba, sendo que os demais monossacarídeos não diferiram entre as duas espécies. Depois da arabinose, o carboidrato com maior IP foi a fucose, seguido de glicose e do polímero lignina de Klason.

Os componentes estruturais de parede celular também mostraram valores muito baixos de plasticidade com algumas diferenças interespecíficas. P. peroba demonstrou sua maior sensibilidade a pleno sol, expressando maior teor de lignina de Klason estimulado pela elevada luminosidade (Syros et al., 2005; Andersson-Gunneras et al., 2006; Möller et al., 2006; Moura et al., 2010). Além da função estrutural, a lignina age como isolante térmico, minimizando o efeito da elevação da temperatura associada à maior intensidade da luminosidade (Akgül et al., 2007). Estruturalmente, a maior sensibilidade de $P$. peroba a 
pleno sol pode ser associada, também, à baixa proporção de arabinose, que foi $42 \%$ menor a pleno sol, enquanto que a maior resistência de $C$. legalis a pleno sol pode estar relacionada com a menor plasticidade da lignina insolúvel e arabinose. Isso sugere que o metabolismo dos componentes estruturais de parede celular de $P$. peroba seja mais vulnerável às variações da intensidade da luminosidade, o que deve exigir maior consumo de energia química em detrimento da velocidade do crescimento (TCR) quando submetida a pleno sol.

Tabela 3. Concentração dos monossacarídeos estruturais, lignina de Klason e lignina solúvel (\% massa seca da parede celular do xilema do caule de plantas de Paratecoma peroba e Cariniana legalis após 60 dias de cultivo em pleno sol e sombra.

\begin{tabular}{|c|c|c|c|c|c|c|}
\hline \multirow{2}{*}{$\begin{array}{c}\text { Monossacarídeos } \\
\text { e lignina }\end{array}$} & \multicolumn{2}{|c|}{ P. peroba } & \multirow[b]{2}{*}{ IP } & \multicolumn{3}{|c|}{ C. legalis } \\
\hline & Pleno sol & Sombra & & Pleno sol & Sombra & IP \\
\hline Glicose & $48 \pm 3^{\mathrm{aA}}$ & $37 \pm 2^{\mathrm{bA}}$ & 0,23 & $49 \pm 2^{\mathrm{aA}}$ & $38 \pm 3^{\mathrm{bA}}$ & 0,22 \\
\hline Xilose & $21 \pm 2^{\mathrm{aA}}$ & $19 \pm 2^{\mathrm{aA}}$ & 0,09 & $20 \pm 1^{\mathrm{aA}}$ & $20 \pm 2^{\mathrm{aA}}$ & 0,00 \\
\hline Fucose & $0,05 \pm 0,01^{\mathrm{aA}}$ & $0,03 \pm 0,01^{\mathrm{aA}}$ & 0,40 & $0,07 \pm 0,01^{\mathrm{aA}}$ & $0,04 \pm 0,01^{\mathrm{aA}}$ & 0,43 \\
\hline Ramnose & $0,16 \pm 0,08^{\mathrm{aA}}$ & $0,14 \pm 0,05^{\mathrm{aA}}$ & 0,12 & $0,19 \pm 0,03^{\mathrm{aA}}$ & $0,18 \pm 0,02^{\mathrm{aA}}$ & 0,05 \\
\hline Arabinose & $0,22 \pm 0,08^{\mathrm{bA}}$ & $0,38 \pm 0,05^{\mathrm{aA}}$ & $0,42^{*}$ & $0,15 \pm 0,01^{\mathrm{aA}}$ & $0,19 \pm 0,02^{\mathrm{aB}}$ & 0,21 \\
\hline Galactose & $0,61 \pm 0,1^{\mathrm{aA}}$ & $0,71 \pm 0,3^{\mathrm{aA}}$ & 0,14 & $0,62 \pm 0,1^{\mathrm{aA}}$ & $0,63 \pm 0,2^{\mathrm{aA}}$ & 0,16 \\
\hline Lignina de Klason & $23 \pm 2,6^{\mathrm{aA}}$ & $19 \pm 2,8^{\mathrm{bB}}$ & 0,23 & $28 \pm 2,5^{\mathrm{aA}}$ & $31 \pm 3,6^{\mathrm{aA}}$ & 0,17 \\
\hline Lignina solúvel & $2,6 \pm 0,6^{\mathrm{aA}}$ & $2,1 \pm 0,8^{\mathrm{aA}}$ & 0,19 & $2,0 \pm 0,5^{\mathrm{aA}}$ & $2,4 \pm 0,6^{\mathrm{aA}}$ & 0,16 \\
\hline Média IP & & & 0,23 & & & 0,17 \\
\hline
\end{tabular}

Letras minúsculas comparam tratamentos dentro de espécie, letras maiúsculas comparam tratamentos entre as espécies e asteriscos $(*)$ comparam o índice de plasticidade (IP) entre as espécies $(\mathrm{P}<0,05, \mathrm{n}=8)$.

A maior proporção de glicose seguida de xilose sugere que a principal classe presente na matriz das hemiceluloses seja do tipo xiloglucano, mais abundante em eudicotiledôneas (Carpita \& McCann, 2000; Hayashi \& Kaidar, 2011). Diferente da lignina, essas maiores frações das hemiceluloses não foram influenciadas pela intensidade da luminosidade para as duas espécies investigadas, sugerindo que as hemiceluloses não tenham relação com o nível de resistência de espécies não pioneiras a pleno sol.

Diferente da hipótese original, os componentes de parede celular mostraram IP equivalente às variáveis de crescimento e anatômicas e, ambas, inferiores à variável relacionada ao indicador de assimilação do carbono (TAL). A maior resistência de $C$. legalis a pleno sol pode ser atribuída à maior TAL e TCR nessa condição e pelo IP dessas taxas $(\geq 6,0)$, IP da densidade estomática (R:PA $\geq 0,3)$ e menor IP do diâmetro do caule, AFE, lignina e arabinose $(\leq 0,2)$. Dessa forma, das duas espécies não pioneiras analisadas, $C$. legalis apresentou características morfológicas e fisiológicas capazes de proporcionar maior resistência a pleno sol, sendo, portanto, indicada para programas de reflorestamento com fins ecológicos ou econômicos.

\section{Conclusões}

C. legalis mostrou maior resistência a pleno sol em relação a $P$. peroba ao mostrar maior taxa de crescimento relativo (TCR) e taxa assimilatória líquida (TAL). Diferente do esperado, o teor de lignina e as proporções dos monossacarídeos das hemiceluloses não foram influenciados pela variação intensa da luminosidade. A plasticidade dos componentes de parede celular foi inferior às variáveis de crescimento e anatômicas. A capacidade de $C$. legalis em se instalar em locais de baixa e elevada luminosidade foi associada ao índice de plasticidade da TAL e TCR $\geq 0,6$, densidade estomática e razão raízes: parte aérea $\geq 0,3$ e diâmetro do caule, área foliar específica, lignina e arabinose $\leq 0,2$.

\section{Agradecimentos}

Os autores agradecem ao Plano Nacional de Apoio ao Desenvolvimento da Botânica-Coordenação de Aperfeiçoamento de Pessoal de Nível Superior do Brasil (PNADB-CAPES), pelo apoio financeiro (Auxílio 1147/2010) e à Reserva Natural Vale do Brasil, pelo fornecimento do material biológico. O primeiro autor agradece ao Conselho Nacional de Desenvolvimento Científico e Tecnológico do Brasil (CNPq) pela concessão de bolsa de produtividade científica (Processo 305447/2012-2). 


\section{Referências}

AKGÜL, M.; ÇÖPÜR, Y.; TEMIZ, S. A comparison of kraft and kraftsodium borohydrate brutia pine pulps. Building and Environment, Oxford, v. 42, p. 2586-2590, 2007. DOI: 10.1016/j. buildenv.2006.07.022.

AMERICAN SOCIETY FOR TESTING AND MATERIALS. ASTM E 1690-01: standard practice for determination of ethanol extractives in biomass. Philadelphia, 2001a.

AMERICAN SOCIETY FOR TESTING AND MATERIALS. ASTM E 1721-01: standard test method for acid insoluble residue in biomass. Philadelphia, 2001b.

AMERICAN SOCIETY FOR TESTING AND MATERIALS. ASTM E 1758-01: standard practice for preparation of biomass for compositional analysis. Philadelphia, 2001c.

ANDERSSON-GUNNERAS, S.; MELLEROWICZ, E. J.; LOVE, J.; SEGERMAN, B.; OHMIYA, Y.; COUTINHO, P. M.; NILSSON, P.; HENRISSAT, B.; MORITZ, T.; SUNDBERG, B. Biosynthesis of cellulose-enriched tension wood in Populus tremula: global analysis of transcripts and metabolites identifies biochemical and developmental regulators in secondary wall biosynthesis. Plant Journal, v. 45, n. 2, p. 144-165, Jan. 2006.

ARENQUE, B. C.; GRANDIS, A.; POCIUS, O.; SOUZA, A. P.; BUCKERIDGE, M. S. Responses of Senna reticulata, a legume tree from the Amazonian floodplains, to elevated atmospheric $\mathrm{CO}_{2}$ concentration and waterlogging. Trees, Structure and Function, Berlin, v. 28, n. 4, p. 1021-1034, 2014. DOI: 10.1007/s00468-0141015-0.

BARROS, F. V.; GOULART, M. F.; TELLES, S. B. S.; LOVATO, M. B.; VALLADARES, F.; LEMOS-FILHO, J. P. Phenotypic plasticity to light of two congeneric trees from contrasting habitats: Brazilian Atlantic Forest versus cerrado (savanna). Plant Biology, Stuttgart, v. 14, p. 208-215, 2012. DOI: 10.1111/j.1438-8677.2011.00474.x.

BRADSHAW, A. D. Unravelling phenotypic plasticity: why should we bother? New Phytologist, Cambridge, v. 170, n. 4, p. 644-648, 2006. DOI: $10.1111 /$ j.1469-8137.2006.01761.x.

BUKATSCH, F. Bemerkungen zur Doppelfarbung: AstrablauSafranin. Mikrokosmos, Stuttgart, v. 61, p. 255, 1972.

CARPITA, N.; McCANN, M. The cell wall. In: BUCHANAN, B. B.; GRUISSEM, W.; JONES, R. L. (Ed.). Biochemistry and molecular biology of plants. Rockville: American Society of Plant Physiologists, 2000. p. 52-89.

CHAMBEL, M. R.; CLIMENT, J.; ALÍA, R.; VALLADARES, F. Phenotypic plasticity: a useful framework for understanding adaptation in forest species. Investigación Agraria: Sistemas Recursos Forestales, Madrid, v. 14, p. 334-344, 2005.

COSGROVE, D. J. Expansive growth of plant cell walls. Plant Physiology and Biochemistry, v. 38, n. 1, p. 109-124, 2000. DOI: 10.1016/S0981-9428(00)00164-9.

ENGEL, V. L. Estudo fenológico de espécies arbóreas de uma floresta tropical em Linhares, ES. 2001. 137 f. Tese (Doutorado em Engenharia Florestal) - Universidade Estadual de Campinas, Campinas.
FENGEL, D.; WEGNER, G. Wood: chemistry, ultrastructure and reactions. Berlin: Walter de Gruyter, 1989.

FRY, S. C.; YORK, W. S.; ALBERSHEIM, P.; DARVILL, A.; HAYASHI, T.; JOSELEAU, J. P.; KATO, Y.; LORENCES, E. P.; MACLACHLAN, G. A.; MCNEIL, M.; MORT, A. J.; REID, J. S. G.; SEITZ, H. U.; SELVENDRAN, R. R.; WHITE, A. L. An unambiguous nomenclature for xyloglucan derived oligosaccharides. Physiologia Plantarum, Copenhagen, v. 89, n. 1, p. 1-3, 1993.

GABURRO, T. A.; ZANETTI, L.V.; GAMA, V. N.; MILANEZ, C. R. D.; CUZZUOL, G. R. F. Physiological variables related to photosynthesis are more plastic than the morphological and biochemistry in non-pioneer tropical trees under constrasting irradiance. Brazilian Journal of Botany, São Paulo, v. 38, n. 1, p. 39-49, 2014. DOI: 10.1007/s40415-014-0113-y.

GIVNISH, T. J. Serotiny, geography, and fire in the Pine Barrens of New Jersey. Evolution, v. 35, p. 101-123, 1981.

GRAY, K. A.; ZHAO, L. S.; EMPTAGE, M. Bioethanol. Current Opinion in Chemical Biology, London, v. 10, p. 141-146, 2006.

HANBA, Y. T.; KOGAMI, H.; TERASHIMA, I. The effect of growth irradiance on leaf anatomy and photosynthesis in Acer species differing in light demand. Plant, Cell \& Environment, v. 25, n. 8, p. 1021-1030, 2002. DOI: 10.1046/j.1365-3040.2002.00881.x.

HAYASHI, T.; KAIDAR, R. Functions of xyloglucan in plant cells. Molecular Plant, v. 4, n. 1, p. 17-24, 2011. DOI: 10.1093/mp/ssq063.

JOHANSEN, D. A. Plant microtechnique. New York: McGrawHill, 1940.

KÖRNER, C. Carbon limitation in trees. Journal of Ecology, v. 91, n. 1, p. 4-17, 2003. DOI: 10.1046/j.1365-2745.2003.00742.x.

LAMBERS, H.; POORTER, H. Inherent variation in growth rate between higher plants: a search for physiological causes and ecology consequences. Advances in Ecological Research, London, v. 23, p. 187-261, 1992.

LORENZI, H. Árvores brasileiras: manual de identificação e cultivo de plantas arbóreas nativas do Brasil. Nova Odessa: Plantarum, 1992. v. 1. 373.

LORENZI, H. Árvores brasileiras: manual de identificação e cultivo de plantas arbóreas nativas do Brasil. Nova Odessa: Instituto Plantarum, 2002. p. 384.

MENDES, M. M.; GAZARINI, L. C.; RODRIGUES, M. L. Acclimation of Myrtus communis to contrasting mediterranean light environments - effects on structure and chemical composition of foliage and plant water relations. Environmental and Experimental Botany, Elmsford, v. 45, p. 165-178, 2001.

MENGARDA, L. H. G.; MILANEZ, C. R. D.; SILVA, D. M.; AGUILAR, M. A.; CUZZUOL, G. R. F. Morphological and physiological adjustments of Brazilwood (Caesalpinia echinata Lam.) to direct solar radiation. Brazilian Journal of Botany, São Paulo, v. 24, p. 161-172, 2012. DOI: 10.1590/S1677-04202012000300003.

MENGARDA, L. H. G.; SOUZA, R. L. F.; CAMPOSTRINI, E.; REIS, F. O.; VENDRAME, W. A.; CUZZUOL, G. R. F. Light as an indicator of ecological succession in Brazilwood (Caesalpinia echinata Lam.). Brazilian Journal of Botany, São Paulo, v. 21, p. 55-64, 2009. DOI: 10.1590/S1677-04202009000100007. 
MÖLLER, R.; BALL, R.; HENDERSON, A.; MODZEL, G.; FIND, J. Effect of light and activated charcoal on tracheary element differentiation in callus cultures of Pinus radiata D. Don. Plant Cell, Tissue and Organ Culture, Dordrecht, v. 85, n. 2, p. 161-171, 2006. DOI: 10.1007/s11240-005-9065-z.

MOURA, J. C. M. S.; BONINE, C. A. V.; VIANA, J. O. F.; DORNELAS, M. C.; MAZZAFERA, P. Abiotic and biotic stresses and changes in the lignin content and composition in plants. Journal of Integrative Plant Biology, v. 52, n. 4, p. 360-376, 2010. DOI: 10.1111/j.1744-7909.2010.00892.x.

NARENDRA, R.; ABDUS, S.; YIQI, Y. Effect of lignin on the heat and light resistance of lignocellulosic fibers. Macromolecular Materials and Engineering, v. 292, n. 4, p. 458-466, 2007. DOI: 10.1002/mame.200600446.

NAVAS, M. L.; GARNIER, E. Plasticity of whole plant and leaf traits in Rubia peregrine in response to light, nutrient and water availability. Acta Oecologica, Paris, v. 23, p. 375-386, 2002. DOI: 10.1016/S1146-609X(02)01168-2.

OGUCHI, R.; HIKOSAKA, K.; HIROSE, T. Leaf anatomy as a constraint for photosynthetic acclimation: differential responses in leaf anatomy to increasing growth irradiance among three deciduous trees. Plant, Cell \& Environment, v. 28, n. 7, p. 916-927, 2005. DOI: $10.1111 /$ j.1365-3040.2005.01344.x

PAULY, M.; KEEGSTRA, K. Cell-wall carbohydrates and their modification as a resource for biofuels. Plant Journal, Oxford, v. 54, n. 4, p. 559-568, 2008. DOI: 10.1111/j.1365-313X.2008.03463.x.

POORTER, L. Light-dependent changes in biomass allocation and their importance for growth for rain forest tree species. Functional Ecology, Oxford, v. 15, n. 1, p. 113-123, 2001. DOI: 10.1046/j.13652435.2001.00503.x.

PORTELA, F. C. S. Influência da luminosidade na ecofisiologia de jequitibá (Cariniana estrellensis (Raddi.) Kuntze) em um gradiente de irradiância, 2012. 91 f. Dissertação (Mestrado em Biologia Vegetal) - Universidade Federal do Espírito Santo, Vitória.

RAES, J.; ROHDE, A.; CHRISTENSEN, J. H.; VAN DE PEER, Y.; BOERJAN, W. Genome-wide characterization of the lignification toolbox in Arabidopsis. Plant Physiology, v. 133, p. 1051-1071, 2003. DOI: $10.1104 /$ pp.103.026484.

RONDON NETO, R. M.; BOTELHO, S. A.; DAVIDE, A. C.; FONTES, M. A. L.; FARIA, J. M. R. Estudos básicos para propostas de tratamentos silviculturais para acelerar o processo de recomposição da vegetação de uma clareira de formação antrópica, em Lavras, MG - Brasil. In: CICLO DE ATUALIZAÇÃO FLORESTAL DO CONESUL, Santa Maria, RS. Anais. Santa Maria, RS: Universidade Federal de Santa Maria, 1999. p. 165-176.

ROSSATO, D. R.; KOLB, R. M. Gochnatia polymorpha (Less.) Cabrera (Asteraceae) changes in leaf structure due to differences in light and edaphic conditions. Acta Botanica Brasilica, Porto Alegre, v. 24, n. 3, p. 133-149, 2012. DOI: 10.1590/S010233062010000300002.

ROZENDAAL, D. M. A.; HURTADO, V. H.; POORTER, L. Plasticity in leaf traits of 38 tropical tree species in response to light: relationships with demand and adult stature. Functional Ecology, Oxford, v. 20, n. 2, p. 207-216, 2006. DOI: 10.1111/j.13652435.2006.01105.x.
SAHA, B. C. Hemicellulose bioconversion. Journal of Industrial Microbial Biotechnology, v. 30, n. 5, p. 279-291, 2003. DOI: 10.1007/s10295-003-0049-X.

SHÄDEL, C.; BLÖCHL, A.; RICHTER, A.; HOCH, G. Quantification and monosaccharide composition of hemicelluloses from different plant functional types. Plant Physiology and Biochemistry, v. 48, n. 1, p. 1-8, 2010a. DOI: 10.1016/j. plaphy.2009.09.008.

SHÄDEL, C.; RICHTER, A.; BLÖCHL, A.; HOCH, G. Hemicellulose concentration and composition in plant cell walls under extreme carbon source-sink imbalances. Physiologia Plantarum, v. 139, n. 3, p. 241-255, 2010b. DOI: 10.1111/j.13993054.2010.01360.x.

SILVA, F. A. Z.; AZEVEDO, C. A. V. A new version of the AssistatStatistical Assistance Software, In: ANNALS of the World Congress on Computers in Agriculture. Orlando: ASAE, 2007. p. 393-396.

SOMERVILLE, C. Biofuels. Current Biology, London, v. 17, p. 115-119, 2007.

SOUZA, C. M.; RIBEIRO, R. V.; PRADO, C. H.; DAMINELI, D. S. C.; SATO, A. M.; OLIVEIRA, M. S. Using network connectance and autonamy analyses to uncover patterns of photosynthetic responses in tropical wood species. Ecological Complexity, v. 9, p. 15-26, 2009. DOI: 10.1016/j.ecocom.2008.10.002.

SOUZA, R. P.; VÁLIO, I. F. M. Seedling growth of fifteen Brazilian tropical tree species differing in successional status. Brazilian Journal of Botany, São Paulo, v. 26, n. 1, p. 35-47, 2003. DOI: 10.1590/S0100-84042003000100005.

SYROS, T. D.; YUPSANIS, T. A.; ECONOMOU, A. S. Expression of peroxidases during seedling growth in Ebenus cretica L. as affected by light and temperature treatments. Plant Growth Regulation, v. 46, n. 2, p. 143-151, 2005. DOI: 10.1007/s10725-005-8087-1

TECHNICAL ASSOCIATION OF THE PULP AND PAPER INDUSTRY. TAPPI 222 om-88: acid-insoluble lignin in wood and pulp. Atlanta, 1998.

THOMPSON, D. S. How do cell walls regulate plant growth? Journal of Experimental Botany, Oxford, v. 56, n. 419, p. 22752285, 2005. DOI: $10.1093 / \mathrm{jxb} /$ eri247.

VALLADARES, F.; ARRIETA, S.; ARANDA, I.; LORENZO, D.; TENA, D.; SÁNCHEZ-GÓMEZ, D.; SUAREZ, F.; PARDOS, J. A. Shade tolerance, photoinhibition sensitivity and phenotypic plasticity of Ilex aquifolium in continental-Mediterranean sites. Tree Physiology, v. 25, n. 8, p. 1041-1052, 2005.

VALLADARES, F.; NIINEMETS, Ü. Shade tolerance, a key plant feature of complex nature and consequences. Annual Review of Ecology, Evolution and Systematics, v. 39, p. 37-257, 2008. DOI: 10.1146/annurev.ecolsys.39.110707.173506.

VALLADARES, F.; WRIGHT, S. J.; LASSO, E.; KITAJIMA, K.; PEARCY, R. W. Plastic phenotypic response to light of 16 congeneric shrubs from a Panamanian rainforest. Ecology, v. 81, p. 1925-1936, 2000. DOI: 10.1890/0012-9658(2000)081[1925:PPRTLO]2.0.CO;2.

WALTER, R. G. Towards an understanding of photosynthetic acclimation. Journal of Experimental Botany, Oxford, v. 56, n. 411, p. 435-447, 2005. DOI: 10.1093/jxb/eri060. 
ZANI, L. B. Caracterização da ontogenia do Pau-Brasil L.

(Caesalpinia echinata Lam.). 2014. 84 f. Dissertação (Mestrado em

Biologia Vegetal) - Universidade Federal do Espírito Santo, Vitória. 
